\title{
EXIT procedure in twin pregnancy: a series of three cases from a single center
}

\author{
Lutgardo García-Díaz', Juan Carlos de Agustín², Antonio Ontanilla, Maria Luisa Marenco ${ }^{5}$, Antonio Pavón ${ }^{4}$, \\ Antonio Losada ${ }^{4}$ and Guillermo Antiñolo ${ }^{1,6^{*}}$
}

\begin{abstract}
Background: Indications for the ex utero intrapartum therapy (EXIT) procedure have evolved and nowadays in addition to secure the airway, obtain vascular access, administer surfactant and other resuscitation medications, EXIT is used to resect cervical or thoracic masses, for extracorporeal membrane circulation (ECMO) cannulation, as well as to rescue maximum intra-thoracic space for ventilation of the remaining functional lung tissue or in cases in which resuscitation of the neonate may be compromised. EXIT procedure in twin pregnancy has been rarely reported and some doubts have been raised about its strategy and safety in such cases.
\end{abstract}

Methods: We reviewed the medical records of 3 twin pregnancy cases where the EXIT procedure have been performed in our center.

Results: The mean gestational age at EXIT procedure was $34+4$ weeks. In two out the three EXIT procedures, the affected twin was delivered first. The average time on placental bypass was 9 minutes. There were no fetal or maternal complications related to the EXIT procedure. All newborns are currently doing well.

Conclusion: In twin pregnancies, prenatal diagnosis combined with the EXIT procedure permits the formulation of a controlled delivery strategy to secure both newborns outcome. In those pregnancies, if intervention can be accomplished without compromise of the normal twin, EXIT can be considered. Our results support that EXIT procedure, if properly planned, safely provides a good outcome for both the fetuses as well as the mother.

Keywords: Prenatal diagnosis, Fetal medicine, Fetal intervention, Twin pregnancy, Ex utero intrapartum therapy (EXIT) procedure

\section{Background}

The ex-utero intrapartum therapy (EXIT) procedure was initially described for the reversal of tracheal occlusion at the time of delivery in fetuses with severe congenital diaphragmatic hernia $(\mathrm{CDH})$ that had undergone inutero tracheal occlusion [1,2]. EXIT allows therapeutic interventions on the fetus while maintaining fetoplacental circulation and thereby maintaining oxygenation. In cases of airway obstruction, the EXIT procedure has proved to be very useful because it avoids the hypoxia, brain injury, and death that can be associated with a

\footnotetext{
* Correspondence: guillermo.antinolo.sspa@juntadeandalucia.es

'Unidad de Gestión Clínica de Genética, Reproducción y Medicina Fetal. Instituto de Biomedicina de Sevilla (IBIS), Hospital Universitario Virgen del Rocío/CSIC/Universidad de Sevilla, 41003 Sevilla, Spain

${ }^{6}$ Centro de Investigación Biomédica en Red de Enfermedades Raras (CIBERER), Sevilla, Spain

Full list of author information is available at the end of the article
}

neonatal airway crisis. The time provided by the EXIT procedure converts an emergent crisis into a controlled situation. Over time, the techniques used in the EXIT procedure have become standardized, enabling surgeons to perform many differente procedures under controlled conditions, while the fetus remains on uteroplacental bypass. Progressively, the EXIT procedure indications have evolved and nowadays in addition to secure the airway, obtain vascular access, administer surfactant and other resuscitation medications, EXIT is used to resect cervical or thoracic masses, for extracorporeal membrane circulation (ECMO) cannulation, as well as to rescue maximum intra-thoracic space for ventilation of the remaining functional lung tissue [3-6].

In twin pregnancies, prenatal diagnosis combined with EXIT permits the formulation of a controlled delivery strategy to secure both newborns outcome. In those 
pregnancies, if intervention can be accomplished without compromise of the normal twin, EXIT can be considered. EXIT procedure in twin pregnancy has been rarely reported [7-10] and some doubts have been raised about its strategy and safety in twin pregnancies. In this paper we report our experience with the EXIT procedure in a series of three twin pregnancies, to our knowledge the largest series from a single center. The results are summarized in Table 1.

\section{Methods}

\section{Exit procedure}

We used a combined technique, general plus epidural anesthesia, to ensure mother and fetus anesthesia during the exit procedures. An epidural catheter is placed to control intraoperative and postoperative pain. General anesthesia induction (remifentanilo, propofol and rocuronio) is followed in rapid sequence by intubation and assisted ventilation. Before the uterine incision deep inhalational anesthesia with sevoflurane is used to maintain uterine relaxation and preserve uteroplacental circulation and fetal gas exchange. A low transverse abdominal incision exposes the uterus, and a sterile intraoperative ultrasound probe maps the position of the placenta and confirms the position of the fetuses. The location of the hysterotomy is determined by the placental locations, and a margin of at least $5 \mathrm{~cm}$ from the lower placental edge is left. We use our uterine progressive distractors and a stapling device (Premium Poly Cs-57 Autosuture ${ }^{\oplus}$ ), to enter into the amniotic sac with minimum uterine bleeding [11]. Fetuses are continuously monitored with fetal echocardiography. After delivery of the second fetus the closure of the uterus and the abdominal wall is performed according to the standard procedure described elsewhere.

\section{Results}

An informed consent was obtained from all the patients for clinical studies. The study and procedures conformed to the tenets of the declaration of Helsinki and were approved by the Institutional Review Boards from the University Hospital Virgen del Rocío of Seville. Expressed consent was signed by all the cases for the publication of their clinical data and images if required.

\section{Case 1}

A 33-year-old, gravida 1, para 0, at 21 weeks' gestation, was referred to for evaluation of an abnormal twin gestation with a facial tumour in one of the fetuses. 2-D, 3-D and 4-D ultrasound showed a bicorionic, biamniotic twin pregnancy with a normal female twin $\mathrm{A}$, and a female twin B with a large asymmetric anterior mass protruding from mouth and nose not affecting the neck area, occluding completely fetal airway and compromising perinatal transition to pulmonary breath at birth. Prenatal diagnosis of epignatus was established. MRI confirmed an epignatus not invading CNS. Once diagnose was established, our Fetal Medicine and Therapy Program multidisciplinary team proposed the parents to perform an ex utero intrapartum treatment procedure to secure the airway through tracheostomy and intubation before delivery. Implications, benefits and risk of the procedure as well as posterior neonatal treatment were discussed in detail. The parents decided to continue the pregnancy and accepted EXIT. Regular ultrasound assessments showed growth of the tumour to a maximum of 93 × 62 × $56 \mathrm{~mm}$. Polyhydramnios developed in the affected twin as soon as 26 weeks's gestation, resulting in uterine irritability, and requiring 3 amnioreduction procedures (at 27 and 30 weeks' gestation and preoperative), tocolytic agents and bed rest. Dexamethasone injections

Table 1 Results of the EXIT procedures in twin pregnancies

\begin{tabular}{|c|c|c|c|}
\hline & CASE 1 & CASE 2 & CASE 3 \\
\hline DIAGNOSIS & Giant epignathus & Congenital diaphragmatic hernia. & Congenital diaphragmatic hernia. \\
\hline AFFECTED TWIN & Twin B & Twin A & Twin A \\
\hline GESTATIONAL AGE AT EXIT (WK) & 34 & $34+4$ & 35 \\
\hline $\begin{array}{l}\text { TIME ON UTEROPLACENTAL } \\
\text { CIRCULATION (MIN) }\end{array}$ & 7 & 7 & 14 \\
\hline EXIT PROCEDURE & Resection and tracheostomy & $\begin{array}{c}\text { Airway intubation and surfactant } \\
\text { administration }\end{array}$ & $\begin{array}{l}\text { Airway intubation and surfactant } \\
\text { administration }\end{array}$ \\
\hline NEONATAL HOSPITAL STAY (DAYS) & 78 & 61 & 22 \\
\hline $\begin{array}{l}\text { PREOPERATIVE MATERNAL } \\
\text { HEMOGIOBIN (g/L) }\end{array}$ & 8.3 & 11.9 & 10.3 \\
\hline $\begin{array}{l}\text { POSTOPERATIVE MATERNAL } \\
\text { HEMOGLOBIN (g/L) }\end{array}$ & 6.8 & 11.3 & 9.7 \\
\hline POSTPARTUM HOSPITAL STAY (DAYS) & 4 & 4 & 4 \\
\hline OUTCOME & $\begin{array}{l}\text { Both twins doing well } \\
7 \text { years after birth }\end{array}$ & $\begin{array}{c}\text { Both twins doing well } 5 \text { years } \\
\text { after birth }\end{array}$ & $\begin{array}{l}\text { Both twins doing well } 2 \text { years } \\
\text { after birth }\end{array}$ \\
\hline
\end{tabular}


were given at 27 weeks of gestation. The mother developed anaemia from 27 weeks' gestation that reduced haemoglobin levels to $83 \mathrm{~g} / \mathrm{L}$ and was treated with ferrous sulphate, $300 \mathrm{mg} /$ day. The woman was admitted at $33+4$ weeks of gestation for a planned delivery due to the high risk of early spontaneous onset of labour and premature rupture of membranes. At 34th week, the patient underwent the EXIT procedure. Twin A was delivered and passed to the neonatal resuscitation team. Due to the breech fetal position, twin B was completely delivered and positioned approximately at placental level. According to prenatal diagnosis, a large asymmetric mass protruding from mouth and nose, occluding completely the foetal airway was confirmed. Surgical excision of the extraoral mass using two fires of a surgical stapling device followed by tracheostomy were performed. Fetal airway was established with a $3-\mathrm{mm}$ endotracheal tube. Then, the umbilical cord was clamped and divided, and twin B was passed to the neonatal resuscitation team. The time from mass excision and fetal tracheostomy and intubation to cord clamping was 7 minutes. The following day, trachea was repaired reversing the tracheostomy. Airway was secured using fiberoptic guided transnasal intubation. Eight days after delivery the patient underwent surgical revision obtaining complete resection of the tumor with ligation of the superior pharyngeal stalk. The newborn was discharged 78 days after birth. The mother was discharged on the fourth day after intervention. Both newborns are currently doing well.

\section{Case 2}

A 33-year-old woman, gravid 2, para 1, with a bichorionic biamniotic twin pregnancy was referred to at 29 weeks' gestation for evaluation of a left-sided congenital diaphragmatic hernia $(\mathrm{CDH})$. Ultrasound showed a normal male fetus $\mathrm{B}$, and a male fetus A with a left-sided $\mathrm{CDH}$ which included a portion of the liver. The lung-to-head ratio (LHR) was 1.2 an Observed/Expected (O/E) LHR was $28 \%$. At $34+4$ weeks' gestation, an EXIT to ECMO procedure was performed. Fetus A was delivered first, airway was securely intubated and surfactant was administered during EXIT (7 minutes), afterwards the fetus B was delivered without problems. Birth's weight were $2443 \mathrm{~g}$ (twin A) and $2260 \mathrm{~g}$ (twin B) respectively. ECMO was not needed and surgical correction of $\mathrm{CDH}$ was performed 48 hours later without complications. Newborn was discharged 61 days after surgical repair. The mother was discharged on the fourth day after intervention. Both newborns are currently doing well.

\section{Case 3}

A 33-year-old woman, gravida 1, with a bichorionic biamniotic twin pregnancy, was referred to at 27 week's because a $\mathrm{CDH}$ in one of the twins complicated by preterm labor.
Ultrasound showed a normal male fetus $\mathrm{B}$, and a male fetus A with the left hemithorax ocupated by stomach, small intestine and the left portion of the liver. LHR was 1.28 and O/E LHR was $28 \%$. Tocolysis was started and betamethasone was administered for lung maturation. MRI confirmed a left sided CDH with liver up. EXIT to ECMO procedure was performed at 35 weeks gestation. Fetus A was delivered first, airway was securely intubated and surfactant was administered during EXIT (14 minutes), afterwards the second fetus was delivered without problems. The weight of the newborn with CDH was $2352 \mathrm{~g}$. Surgical correction was performed without complications 24 hours later. Newborn was discharged 21 days after surgical repair. The mother was discharged on the fourth day after intervention. Both newborns are currently doing well.

\section{Discussion}

Over the past 25 years, fetal surgery has evolved into a multidisciplinary specialty capable of improving perinatal outcome for a wide variety of diseases. Recent advances allow to accurately diagnose as well as treat a number of fetal anomalies while preserving maternal safety. The extensive use of prenatal ultrasound has resulted in the increased identification of a number of fetal disorders that have a direct impact in the perinatal management of the fetus and the subsequent outcome. In the last few years, the use of the EXIT procedure has been further expanded to include fetal anomalies where neonatal resuscitation may be compromised, including large thoracic lesions, bilateral hidrothorax, $\mathrm{CDH}$, unilateral pulmonary agenesis, and cardiac lesions [4-7].

Twin pregnancy increases EXIT procedure complexity. In those cases, the control of key elements of an EXIT procedure requires an extreme coordination between all the members of the multidisciplinary team.

When using the EXIT procedure in a twin gestation, the risk should be borne by the affected twin. Priority should always be given to the normal twin in case of risk or complication. However, priority does not mean to necessarily deliver the normal twin first. In our experience, adequate uterine relaxation and careful monitoring of both fetuses and the mother, as well as a good coordination of the team allows treatment of the affected twin before delivery of the unaffected one without risk. Planning and coordination among the multidisciplinary team members during each phase of the EXIT procedure is the key for a successful outcome in those cases.

\section{Conclusions}

In conclusion, in our series EXIT procedure in twin pregnancy have had very good results. Those results support that in twin pregnancy EXIT procedure, if properly planed, safely provides a good outcome for both the fetuses as well as the mother. 


\section{Competing interest}

The authors declare that they have no competing interests.

\section{Authors' contributions}

LG-D and GA carried out the prenatal diagnosis of all the cases here presented. MLM and AO were in charge of the anesthesiologist procedures. JCA, AL and AP performed the postnatal treatment of the cases. GA coordinated and supervised all the procedures. LG-D and GA drafted the manuscript. All authors have read and approved the final manuscript.

\section{Author details}

'Unidad de Gestión Clínica de Genética, Reproducción y Medicina Fetal. Instituto de Biomedicina de Sevilla (IBIS), Hospital Universitario Virgen del Rocío/CSIC/Universidad de Sevilla, 41003 Sevilla, Spain. ${ }^{2}$ Unidad de Gestión Clínica de Cirugía Infantil, Hospital Universitario Virgen del Rocío, 41013 Sevilla, Spain. ${ }^{3}$ Servicio de Anestesiología Hospital Infantil, Hospitales Universitarios Virgen Del Rocío, 41013 Sevilla, Spain. ${ }^{4}$ Unidad De Gestión Clínica De Neonatología, Hospital Universitario Virgen Del Rocío, 41013 Sevilla, Spain. ${ }^{5}$ Servicio de Anestesiología Hospital de La Mujer, Hospital Universitario Virgen Del Rocío, 41013 Sevilla, Spain. ${ }^{6}$ Centro de Investigación Biomédica en Red de Enfermedades Raras (CIBERER), Sevilla, Spain.

Received: 23 May 2014 Accepted: 16 July 2014

Published: 30 July 2014

\section{References}

1. Harrison MR, Adzick NS, Flake AW, VanderWall KJ, Bealer JF, Howell LJ, Farrell JA, Filly RA, Rosen MA, Sola A, Goldberg JD: Correction of congenital diaphragmatic hernia in utero VIII: response of the hypoplastic lung to tracheal occlusion. J Pediatr Surg 1996, 31:1339-48.

2. Flake AW, Crombleholme TM, Johnson MP, Howell L, Adzick NS: Treatment of severe congenital diaphragmatic hernia by fetal tracheal occlusion: clinical experience with fifteen cases. Am J Obstet Gynecol 2000, 183:1059-66.

3. Hedrick HL, Flake AW, Crombleholme TM, Howell L, Johnson MP, Wilson RD, Adzick NS: The ex utero intrapartum therapy for high-risk fetal lung lesions. J Pediatr Surg 2005, 40:1038-44.

4. Hedrick HL, Flake AW, Crombleholme TM, Howell L, Johnson MP, Wilson RD, Adzick NS: Ex utero intrapartum treatment with extracorporeal membrane oxygenation for severe congenital diaphragmatic hernia. J Pediatr Surg 2007, 42:98-104.

5. Hedrick HL: Ex utero intrapartum therapy. Semin Pediatr Surg 2003, 10:190-5.

6. Bouchard S, Johnson MP, Flake AW, Howell LJ, Myers LB, Adzick NS, Crombleholme TM: The EXIT procedure: experience and outcome in 31 cases. J Pediatr Surg 2002, 37:418-26.

7. Antiñolo G, De Agustin JC, Losada A, Marenco ML, Garcia-Diaz L, Morcillo J: Diagnosis and management of fetal intrapericardial Morgagni diaphragmatic hernia with massive pericardial effussion. J Pediatr Surg 2010, 45(2):424-6.

8. Antiñolo G, de Agustín JC, Losada A, Ontanilla A, Perla AG: Diagnosis and management of a large oropharyngeal teratoma (epignathus) in a twin pregnancy. Int J Gynaecol Obstet 2009, 104(2):143-4.

9. Liechty KW, Crombleholme TM, Weiner S, Bernick B, Flake AW, Adzick NS: The ex utero intrapartum treatment procedure for a large fetal neck mass in a twin gestation. Obstet Gynecol 1999, 93(5 Pt 2):824-5.

10. Midrio P, Zadra N, Grismondi G, Suma V, Pitton MA, Salvadori S, Gamba P: EXIT procedure in a twin gestation and review of the literature. Am J Perinatol 2001, 18(7):357-62.

11. Marenco ML, Márquez J, Ontanilla A, García-Díaz L, Rivero M, Losada A Torrejón R, Sainz JA, Antiñolo G: Intrauterine myelomeningocele repair: experience of the fetal medicine and therapy program of the Virgen de Rocío University Hospital. Rev Esp Anestesiol Reanim 2013, 60(1):47-53.

doi:10.1186/1471-2393-14-252

Cite this article as: García-Díaz et al: EXIT procedure in twin pregnancy: a series of three cases from a single center. BMC Pregnancy and Childbirth 2014 14:252.

\section{Submit your next manuscript to BioMed Central and take full advantage of:}

- Convenient online submission

- Thorough peer review

- No space constraints or color figure charges

- Immediate publication on acceptance

- Inclusion in PubMed, CAS, Scopus and Google Scholar

- Research which is freely available for redistribution 